Article

\title{
An Assessment of Ice Effects on Indices for Hydrological Alteration in Flow Regimes
}

\author{
Knut Alfredsen \\ Department of Civil Engineering, Norwegian University of Science and Technology, 7491 Trondheim, Norway; \\ knut.alfredsen@ntnu.no; Tel.: +47-73-594-757
}

Received: 31 October 2017; Accepted: 21 November 2017; Published: 23 November 2017

\begin{abstract}
Preserving hydrological variability is important when developing environmental flow regimes, and a number of tools have been developed to support this process. A commonly applied method is the index of hydrological alteration (IHA), which describes a set of indices that can be used to assess changes in flow regimes. In cold climate regions, river ice can have large effects on flow regimes through frazil and anchor ice formation, ice cover formation, and ice break-up, and the impact of this is usually not included in the commonly used indexes. However, to understand the effect of ice formation and the break-up on the flow regime, the ice effects on the hydrology should be considered when assessing winter alteration indexes. This paper looks at the effects of river ice on winter flow conditions using data from Norwegian rivers, and discusses these effects in relation to hydrological variability. This paper also shows how indexes can be used to classify ice-induced variability, how this should be used to avoid ice-induced effects in the current analysis, and how this can be combined with the current indices to improve the winter flow regime classification. The findings from this paper show that frazil- and anchor-induced raises of the water level have a large impact on the perceived flow in winter, producing higher flow and deeper water than what the open water conditions discharge could do. Corresponding to this, winter lows connected to ice-induced high flows at other locations are also common. Finally, issues related to the assessment of the temporal and spatial effects of ice formation are discussed.
\end{abstract}

Keywords: river ice; index of hydrological alteration; river regulation; environmental flow

\section{Introduction}

The importance of preserving hydrological variability in environmental flow regimes has been described by several authors, e.g., [1,2], and methods to assess and preserve flow regime variability in environmental flows are suggested [3]. The described problems with preserving hydrological variability in environmental flow regimes are valid for all kinds of encroachments on river regimes. Norway produces more than $96 \%$ of its electrical energy from hydropower and has several large-scale hydropower developments that have wide ranging effects in the affected river systems. Processes related to the implementation of the European Union Water Framework Directive and the upcoming relicensing of existing hydropower systems drive the need for better information on the impact of regulation and the development of better methods for mitigating changes in flow regimes. Numerous methods of different types and on different scales are developed for assessing impacts and designing environmental flows, e.g., [4,5]. One method used is the computation of hydrological indices that describes variability in the hydrological regime [2]. The various indices can be linked to environmental performance [6], and effects of changes in flow on the environment can be assessed. Applying these indices before (natural conditions) and then after flow changes provides a measure of change and a foundation for finding mitigation, and a basis for further and more detailed analysis of the impacts. Probably the best known method is the Index of Hydrological Alteration (IHA) 
described by Richter et al. [7], a total of 33 indexes describing components of the flow regime relevant for ecological assessment. Table 1 shows the category of indexes suggested by Richter. This method has gained some use and has been developed into a software tool for assessment and evaluation of the before and after situation in regulated rivers. An adapted version of this method is used as a component of the environmental flow methodology recently developed in Norway [8], and also in the methodology for hydro-morphological assessment with regard to the implementation of the water framework directive [9].

Table 1. The index of hydrological alteration (IHA) parameters used in the Norwegian assessment method (adapted from [7] with permission from John Wiley and Sons).

\begin{tabular}{|c|c|c|}
\hline IHA-Group & Regime Characteristics & Parameter \\
\hline Magnitude of monthly flow & $\begin{array}{l}\text { Magnitude } \\
\text { Timing }\end{array}$ & Monthly means \\
\hline $\begin{array}{l}\text { Magnitude and duration of } \\
\text { annual extremes }\end{array}$ & $\begin{array}{l}\text { Magnitude } \\
\text { Duration }\end{array}$ & $\begin{array}{l}\text { Annual 1-,3-,7-, and 30-day minimum and maximum. } \\
\text { Seasonal minimums and maximums }\end{array}$ \\
\hline Timing of annual extremes & Timing & Julian day of minimum and maximum events \\
\hline $\begin{array}{l}\text { Frequency and duration of } \\
\text { high and low pulses }\end{array}$ & $\begin{array}{l}\text { Frequency } \\
\text { Magnitude } \\
\text { Duration }\end{array}$ & $\begin{array}{c}\text { Number of high pulses, number of low pulses, mean } \\
\text { duration of pulses }\end{array}$ \\
\hline Rate and frequency of changes & $\begin{array}{c}\text { Frequency } \\
\text { Rate of change }\end{array}$ & Number of rises, number of falls, means of changes \\
\hline
\end{tabular}

For assessment in cold regions, it is important to note that the common description of hydrological indexes of alteration $[7,10]$ does not consider the significant effect formation of river ice on the flow conditions during winter. The formation and break-up of river ice can have a significant effect on the water level and flow regime in rivers due to the storage and release of water when ice forms and breaks up. Particularly, during freeze-up, ice can lead to large variability in water levels along the river under stable discharge conditions. A consequence of this is that the in-stream habitat can differ between summer and winter for the same discharge. For cold climate regions, knowledge of ice should therefore be combined with the open water hydrological variability analysis to ensure that relevant ice effects on the flow regime are taken into account in environmental flow analysis. This is particularly the case for rivers regulated for hydropower, since production releases have a significant effect on the ice regime after regulation [11]. Research and data on discharge and river ice is most common in larger rivers from Canada and USA, but recent research has provided insights on the formation of ice and the effects ice has on the flow and related hydraulic parameters in rivers of the size most commonly found in Norway [12-16]. Stickler, Alfredsen, Linnansaari, and Fjeldstad [14] show how formation of anchor ice dams in the river Sokna in Norway transform the hydraulic conditions, and thereby the available habitat, under relatively constant discharge conditions. Shallow, fast riffle areas were transformed into a succession of deeper pools that eventually formed a continuous ice cover over the reach. During the formation process, the water level in this reach was considerably higher than what it would have been with the same discharge under open water conditions, and as a consequence anchor ice damming at this site would lead to ice-induced low flows further downstream. Similar results were found by Turcotte and Morse [15], who also compared three sections of a different size and documented the similarities and differences in ice formation between scales from river to creek. Turcotte, Morse, Dube, and Anctil [16] quantified the ice formation in small rivers combining an energy balance model with river hydraulics providing a method to extend the assessment to sections where direct observations don't exist. Lind, Alfredsen, Kuglerova, and Nilsson [12] used a statistical modelling approach to link ice formation on 25 river-reaches in Sweden to parameters easily obtainable from meteorological and geographical information, thereby providing tools for assessing ice formation over larger spatial scales. As discussed above, ice can induce high water conditions and even floods during freeze-up. 
In addition, ice can also induce flood levels during break-up, particularly in association with ice jamming [17]. For a further discussion on low flows and the corresponding channel storage effects, see [18].

There are both direct and indirect effects on the environment from ice formation which should be incorporated in an environmental assessment. It is therefore necessary to link the relevant hydrological indices to the response of the environment. For salmonid fish, ice formation and break-up can influence habitat availability, behaviour, and apparent survival, while a stable ice cover is often considered beneficial. A reduced or removed surface ice cover due to hydropower regulation in rivers where a stable ice cover is the normal can have a negative impact on Atlantic salmon [19]. Summaries of the general impact of ice on fish can be found in reviews by Brown et al. [20,21], and Heggenes et al. The authors of [22] recently summarized the knowledge on the relations between fish, hydropower development, and ice conditions. Formation of ice may also have effects on the terrestrial environment and the river floodplains. Lind and Nilsson [23] found a higher diversity of riparian plants in rivers with flooding related to anchor ice formation, and also a difference in aquatic plants where anchor ice formed. Lind et al. [24] review the relationship between ice dynamics on riparian and aquatic vegetation and find evidence of both a direct physical impact and the physiological effects of ice on plant communities. Lesack and Marsh [25] show the relationship between flood peaks and water renewal in adjacent lakes on the Mackenzie delta, and how ice jams during the spring flood influence this process. Ice-induced effects on the flow regime can have a negative impact on the river environment, but also beneficial effects, which should be addressed in an environmental assessment. There is, therefore, a need to develop tools to do this, since omitting ice effects would eliminate effects like ice-induced flooding during freeze up, flooding during break up, the duration of the ice-covered period, and ice-induced low flows during freeze up, which are known to appear during the winter period in cold climates. In a study of the Peace-Athabasca delta, Canada, Monk et al. [26] added cold climate relevant parameters to a subset of the original IHA parameters to assess environmental change also related to the ice processes. This work was later developed into the Cold-regions Hydrological Indicators of Change (CHIC) [27]. This is a suite of indexes that characterizes the impact of ice on the flow regime, and, combined with a selection of IHA indexes, it covers the important features of a cold climate flow regime. This development work used the Mackenzie river, Canada as a case study. Table 2 shows the CHIC revised ice indexes.

Table 2. Ice influenced indices in Cold-regions Hydrological Indicators of Change (CHIC), after [27].

\begin{tabular}{ccc}
\hline Ice Feature & $\begin{array}{c}\text { Regime } \\
\text { Characteristics }\end{array}$ & Parameter \\
\hline $\begin{array}{c}\text { Freeze-up } \\
\text { Break-up }\end{array}$ & $\begin{array}{c}\text { Timing } \\
\text { Magnitude }\end{array}$ & Date of break-up and freeze-up, magnitude of flow at freeze-up and break-up. \\
\hline $\begin{array}{c}\text { Ice-induced high } \\
\text { and low flow }\end{array}$ & $\begin{array}{c}\text { Timing } \\
\text { Magnitude }\end{array}$ & $\begin{array}{c}\text { 1-day minimum ice-induced flow, 1-day maximum ice-induced flow, date of 1-day } \\
\text { max and min, peak water level during ice-influenced period, date of peak water level. }\end{array}$ \\
\hline Ice season & Duration & Duration of ice-influenced period. \\
\hline
\end{tabular}

To compute the ice-related indexes, Peters, Monk, and Baird [27] used data from Environment Canada that carried a flag in the meta data, which showed if the measurement was influenced by ice or not. For Norway, such data is not available from the national discharge database, and data on ice duration is just available for a few rivers and has uncertainties that are difficult to assess [28]. On the other hand, ice-corrected data based on manual correction procedures are available from the national database on a daily scale and provide an alternative to data marked as ice-influenced.

The objective of this paper is to describe the effect of river ice on hydrological flow indices and suggest additional indices to measure ice effects, particularly those that focus on smaller rivers with short duration ice events. This paper also describes how indices can be used to both describe ice effects on flow in unregulated gauges and how to compare ice-induced hydrological variability before and after flow regulation. Further, this paper discusses temporal and spatial issues related to ice indices 
and how indices can be used to improve our understanding of winter flow regimes. Lack of data is a common issue related to winter and ice, and this paper discusses strategies for evaluating ice using air temperature, together with the flow record, to assess periods where ice effects on the flow can occur. This paper is an extended version of initial work presented at the CRIPE 2017 conference [29].

\section{Materials and Methods}

\subsection{Study Sites and Data}

Flow data is collected from the HYDRA II database at the Norwegian Water Resources and Energy Directorate (NVE). Ice-on and ice-off data is not available for the gauges used in this study, but NVE provides ice-adjusted daily data for each of the gauges. Ice adjustments are carried out retroactively based on air temperature and neighboring gauges if possible, in which flow events in cold periods are evaluated and removed if they cannot be explained by changes in natural inflow. For each gauge, both the ice adjusted data set and the raw data set (before adjustment) was downloaded and combined to detect periods where ice have been considered to be present in the data. From this combined data set, the ice season and ice effects on the flow can be derived and the indexes computed. For small rivers, ice processes may best be detected on a sub-daily time step, but only daily data have been corrected for ice. For periods where hourly data are analyzed, the daily corrected data are disaggregated into hourly resolution before the analysis is carried out. The corrections in the data are checked against air temperature, and air temperature is further evaluated as a tool for detecting ice periods in the case for which no flagged or corrected data is available for the site. The flow data used in the development and analysis is collected from the unregulated gauges at Hugdal Bru in Sokna $\left(10.24^{\circ} \mathrm{E}, 62.99^{\circ} \mathrm{N}\right)$ and Eggafoss in Gaula $\left(11.18^{\circ} \mathrm{E}, 62.89^{\circ} \mathrm{N}\right)$, and for the regulated gauge at Syrstad/Bjørset in Orkla $\left(9.73^{\circ} \mathrm{E}, 63.03^{\circ} \mathrm{N}\right)$, all gauges are located in middle Norway. Hugdal bru covers a catchment area of $545 \mathrm{~km}^{2}$ and has a mean flow of $12.7 \mathrm{~m}^{3} \cdot \mathrm{s}^{-1}$. Eggafoss has a catchment area of $655 \mathrm{~km}^{2}$ and an annual mean flow of $17.1 \mathrm{~m}^{3} \cdot \mathrm{s}^{-1}$. Syrstad has a catchment area of $2280 \mathrm{~km}^{2}$ and an annual mean flow of $48.6 \mathrm{~m}^{3} \cdot \mathrm{s}^{-1}$. Figure $1 \mathrm{~A}$ shows the location of the study sites. Syrstad is regulated by several reservoirs and power plants upstream and has a redistributed flow regime over the year with higher winter flow and reduced spring and early summer flow. The data from Syrstad/Bjørset was used to evaluate regulation impacts on the flow regime. The winter period used in all analysis is defined from 1st of October to the 31 March. Data for air temperature is collected from the Norwegian Meteorological Institute. For Syrstad/Bjørset, data from 2000 to 2016 is used as the regulated period and 1970-1980 as the unregulated period. For the two other unregulated sites, data from 2000 to 2016 is used.

\subsection{Analysis and Extended Indices}

Looking at the open-water indexes, e.g., the Index of Hydrological Alteration (IHA), analysis of ice reduced data alone would underestimate winter high flow periods and probably also miss potential short low flow periods. Similarly, using uncorrected data without allowing for ice effects, ice-driven high flows would bias the computation of winter low flow and the duration of winter low flow periods. The issue of winter high flow periods is addressed by Peters, Monk, and Baird [27] as timing and magnitude. For smaller rivers and, particularly, regulated rivers with an unstable ice cover, indices describing the frequency and duration of such episodes are necessary, since an ice-driven variability in the flow regime could influence a number of ecological processes. The frequency of such events would also be an indicator of the stability of the ice cover in the reach.

During freeze-up, periods of low flow can be experienced, as ice stores water upstream both as ice and in temporary ice dams [30]. This effect is also identified by Peters, Monk, and Baird [27], and indexes for magnitude and timing are described. Here, indexes for frequency and duration are added, particularly to handle the unstable ice regime experienced in many regulated rivers. Similarly to the high flow, ice-induced low flows are mainly estimated by comparing the raw and corrected data, and, in cases where there are no available air temperature changes in the gradient of the recession, 
hydrograph is used to detect drops in the flow caused by ice. For small streams, the rate of change of the water level related to such low flows can be significant, and the maximum rate of change is computed following similar procedures, as for hydropeaking analysis [31].

Freeze-up and break-up indices are computed similarly to Peters, Monk, and Baird [27] (see Table 2). For many Norwegian rivers, this is a difficult parameter to compute, since data for ice formation and breakup is not available, and this parameter is not easily derived from the corrected data or from temperature either. An alternative method is to use the zero isotherm using the method described in Gebre and Alfredsen [32]. There are significant uncertainties in this approach that must be considered when data is used.

In rivers regulated for hydropower, particularly high-head systems [22], the stability of the ice cover could be a very important parameter for assessing ecological impacts [33]. The assessment of ice cover stability is an interaction between winter flow (magnitude and stability), local climate, and water temperature. This would need a more comprehensive assessment procedure, e.g., by modelling, than the other ice related indexes. However, indications of the stability of the ice cover can be derived from the frequency and magnitude of ice-induced high flows during the winter period.

The computation of indices is mainly based on utilizing the raw data series, with ice effects present at an hourly time resolution and the ice-reduced data series at a daily resolution. To be identified as a peak, the duration of the peak must be long enough so that the daily average of the hourly time series exceeds the ice corrected series for that specific day. Thereby, we avoid classifying natural peaks that are removed by averaging the hourly series into a daily series. To further control the detection of a peak and avoid noise from minor fluctuations, a user-defined threshold for when a deviation between the ice-reduced and ice-influenced series is considered a peak is defined, see Figure 1B. This ensures that only peaks above a certain size are counted. For the comparison, in which both series are on a daily resolution, this is not an issue and all; differences between the raw and the corrected data are assumed to be ice-induced.

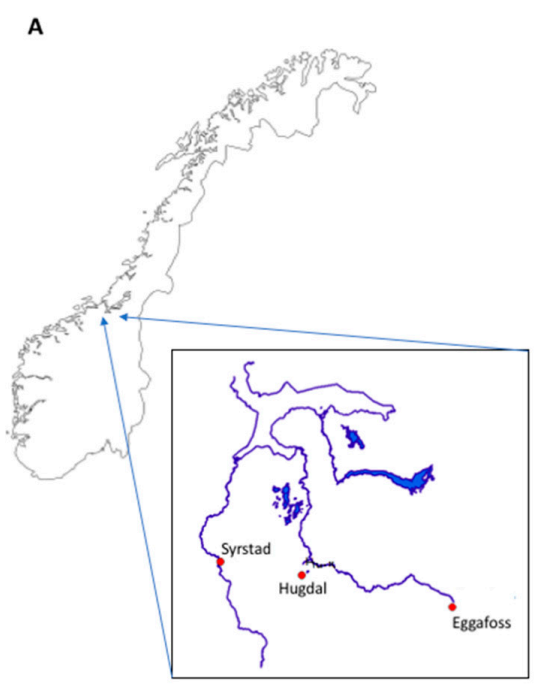

B

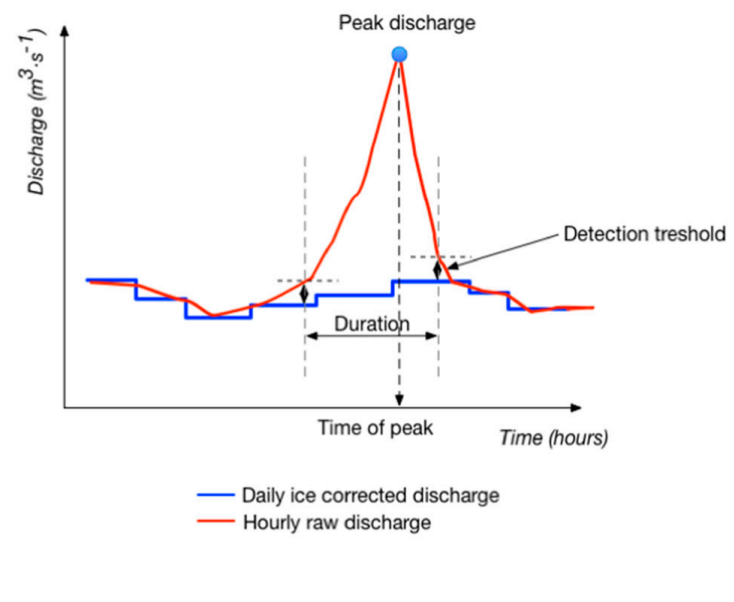

Figure 1. Study sites (panel (A)), and the principle of detecting ice-induced peaks and their characteristic features from a combination of a daily ice-reduced series (blue) and a raw data series (red) (panel (B)). For each year, the maximum peak level and the time of the maximum peak are derived from all yearly events. The detection threshold marked on the figure eliminates effects of small fluctuations on the detected peaks. This is a schematic figure only; therefore, there are no values on the axes.

The air temperature is used as a control to check that ice-induced peaks appear in periods in which the temperature is at zero or lower; however, such periods could also be used to directly detect ice-induced peaks in the case in which no meta data on the ice season or ice-corrected data is available. 
As mentioned, in the case in which hourly raw data is combined with daily resolution-corrected data, it is important to take into consideration that the averaging of hourly data into the daily series that is ice-corrected might mask instantaneous, short-duration natural peaks found in the hourly data set. These deviations may not be captured by the detection threshold described above. To account for this, in situations in which the average of the hourly values in a day and the constant daily value is similar, peaks are not classified as ice-induced.

The analysis of the data is done using the R software (version 3.3.1) [34].

\section{Results}

Figure 2 shows a hydrograph with ice-reduced data (blue), with a time resolution of one day and raw data (red) with an hourly resolution taken from the regulated Syrstad gauge. The large variability of flow over the winter period is caused by the operation of the hydropower system. Key indices are marked on the figure, blue circles indicate high peaks, green circles indicate low peaks, and open circles indicate peaks in the hourly series that are considered to be instantaneous and subsequently lost in the daily data series because of averaging. These are not included in the following analysis. The duration is computed as the width of each peak within the detection threshold, and counting the high and low peaks provides the frequency of events.

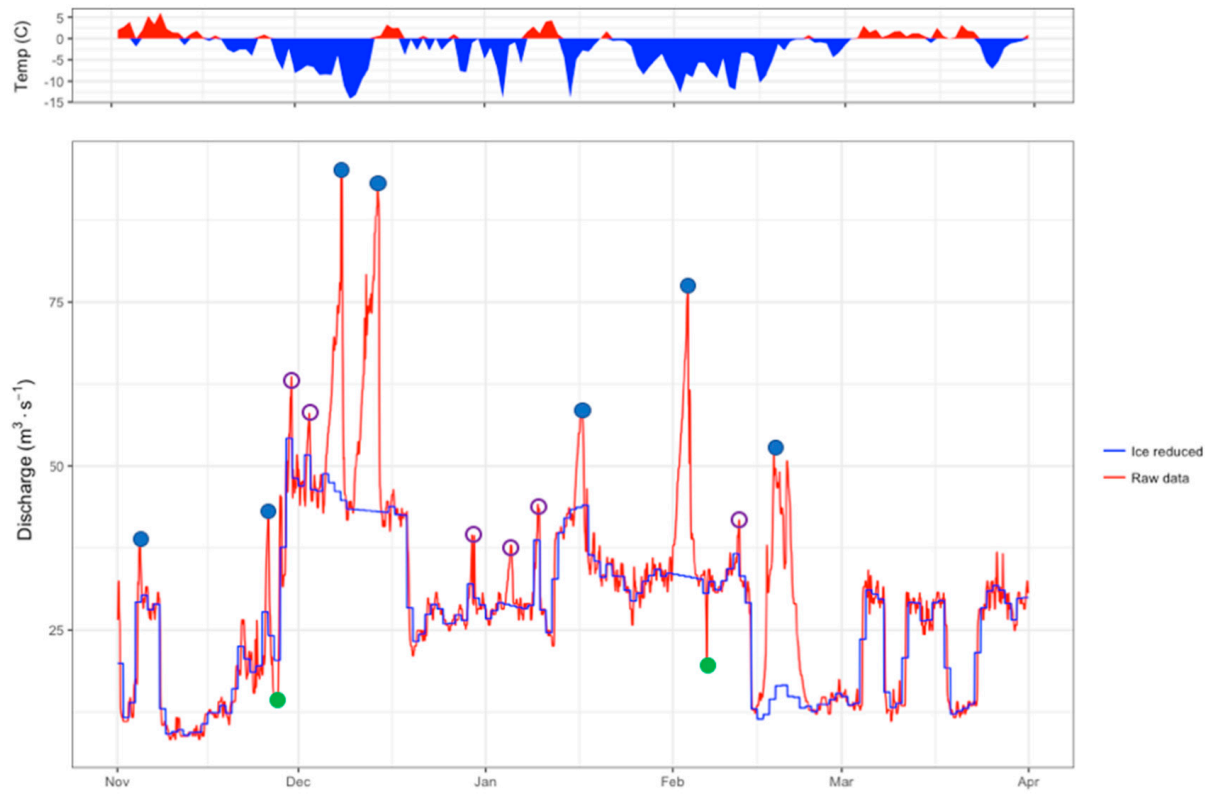

Figure 2. Air temperature (top panel) and identified peaks for one year at Syrstad (lower panel). Open circles are peaks that are considered natural, closed blue circles high peaks due to ice, and closed green circles are low peaks. Note that the variability of flow is driven by hydropower releases.

The formation of the identified ice-induced peaks on Figure 2 coincides with periods of cold weather and shows that these peaks are driven by frazil and anchor ice accumulation at the gauge site. It is also worth noting that the peaks seem to appear independent of the volume flow in the river, which, for this winter, clearly shows the effect of hydropower operation. The indices for the high events registered in Figure 2 (marked by blue circles) are summarized in Table 3. All event data is presented in $\mathrm{m}^{3} \cdot \mathrm{s}^{-1}$; this includes the rise and fall of the hydrograph (in $\mathrm{m}^{3} \cdot \mathrm{s}^{-1} \cdot \mathrm{h}^{-1}$ ), in order to be consistent with the indices hydrological alteration commonly used, and since discharge is usually more readily available for these sites than water level. Data can easily be converted to water level in meters above sea level by utilizing the stage-discharge curve for the gauge. For evaluation purposes, e.g., purposes related to rises and falls, a conversion to water level can be a useful for computing, e.g., loss of wetted area or loss of habitat at the site. 
Table 3. Summary of characteristic data for the event shown in Figure 2. A threshold of $10 \mathrm{~m}^{3} \cdot \mathrm{s}^{-1}$ is used, and only events with a duration of more than $5 \mathrm{~h}$ are shown in the table.

\begin{tabular}{cccccc}
\hline Start Event & Peak Date & $\begin{array}{c}\text { Peak } \\
\left(\mathbf{m}^{\mathbf{3}} \cdot \mathbf{s}^{-\mathbf{1}} \mathbf{)}\right.\end{array}$ & $\begin{array}{c}\text { Duration } \\
\mathbf{( h )}\end{array}$ & $\begin{array}{c}\text { Max Rise } \\
\left(\mathbf{m}^{\mathbf{3}} \cdot \mathbf{s}^{-\mathbf{1}} \cdot \mathbf{h}^{-\mathbf{1}} \mathbf{)}\right.\end{array}$ & $\begin{array}{c}\text { Max Drop } \\
\left(\mathbf{m}^{\mathbf{3}} \cdot \mathbf{s}^{\mathbf{- 1}} \cdot \mathbf{h}^{-\mathbf{1}} \mathbf{)}\right.\end{array}$ \\
\hline 25.11 19:00 & $26.1101: 00$ & 43.2 & 10 & 0.97 & 4.33 \\
06.12 05:00 & $08.1205: 00$ & 95.2 & 54 & 14.5 & 19.1 \\
11.12 03:00 & $14.1203: 00$ & 93.0 & 80 & 7.7 & 25.9 \\
16.01 08:00 & $16.0119: 00$ & 59.1 & 22 & 0.95 & 2.2 \\
01.02 16:00 & $03.0212: 00$ & 78.1 & 57 & 10.8 & 14.8 \\
16.02 10:00 & $17.0217: 00$ & 53.7 & 124 & 9.8 & 3.3 \\
\hline
\end{tabular}

Over the winters from $2000 / 2001$ to $2015 / 2016$, the maximum ice-induced peak was $289.7 \mathrm{~m}^{3} \cdot \mathrm{s}^{-1}$, while the maximum difference between ice corrected discharge and the ice-induced peak was $238.9 \mathrm{~m}^{3} \cdot \mathrm{s}^{-1}$, with an average of $35.3 \mathrm{~m}^{3} \cdot \mathrm{s}^{-1}$. The median duration of all events longer than $5 \mathrm{~h}$ was $11 \mathrm{~h}$. The average duration was $84 \mathrm{~h}$, a number strongly affected by two cold years in which nearly the entire record was corrected. In such cases, the raw flow data would significantly overestimate the inflow to the river, while on the other hand the corrected flow record would underestimate the actual environmental conditions. It is particularly for events of long duration that an evaluation of the ice effects is important.

Figure 3 shows a comparison between flow records from the Syrstad gauge in panel A and the Hugdal bru gauge in panel B. In the Syrstad case, several peaks are seen forming in cold periods, raising the discharge above the correct discharge in the river, which is controlled by releases from the power plant. For the Hugdal Bru case (panel B), two freeze-up events are detected in November and December, separated by what is, most likely, drainage of the anchor ice dam formed at the gauge site (indicated by increase in temperature and fast drainage). The two other peaks occur during milder periods and could be effects of temporary ice jams at the gauge site, showing another type of event in which ice processes alter the discharge in the river outside of the natural stage-discharge relationship. The ice-controlled data for Hugdal bru shows a natural recession into a low winter flow.

A
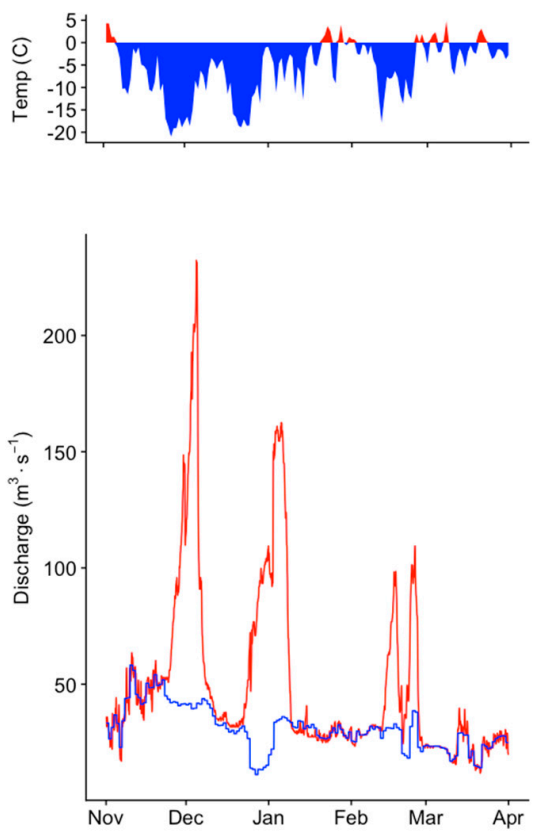
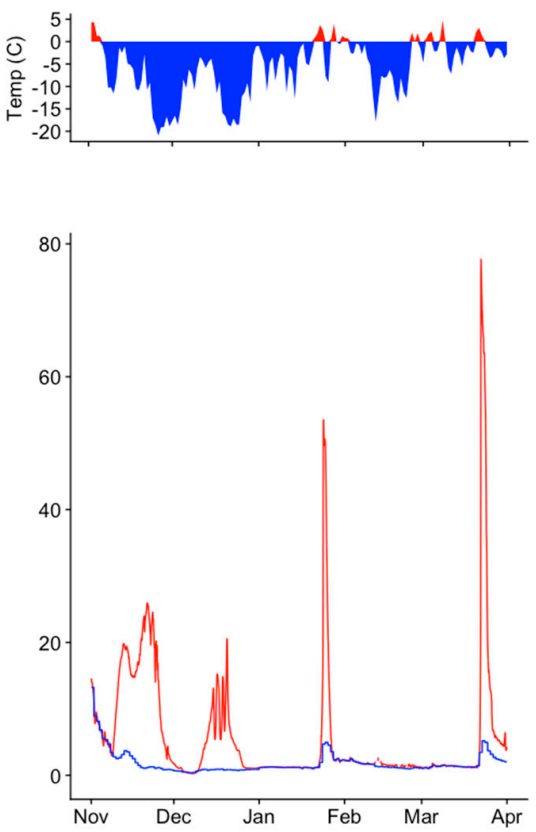

Figure 3. Comparison of flow records from the regulated Syrstad gauge (A) and the unregulated Hugdal Bru gauge (B) for the winter 2010/2011. 
For many practical comparisons, hourly data is not available, particularly in cases in which older discharge records are needed for the evaluation of pre- and post-regulation effects on the flow. It is, therefore, necessary to use ice adjusted daily data for the assessment. Figure 4 shows a comparison for the Syrstad gauge between daily and hourly data.

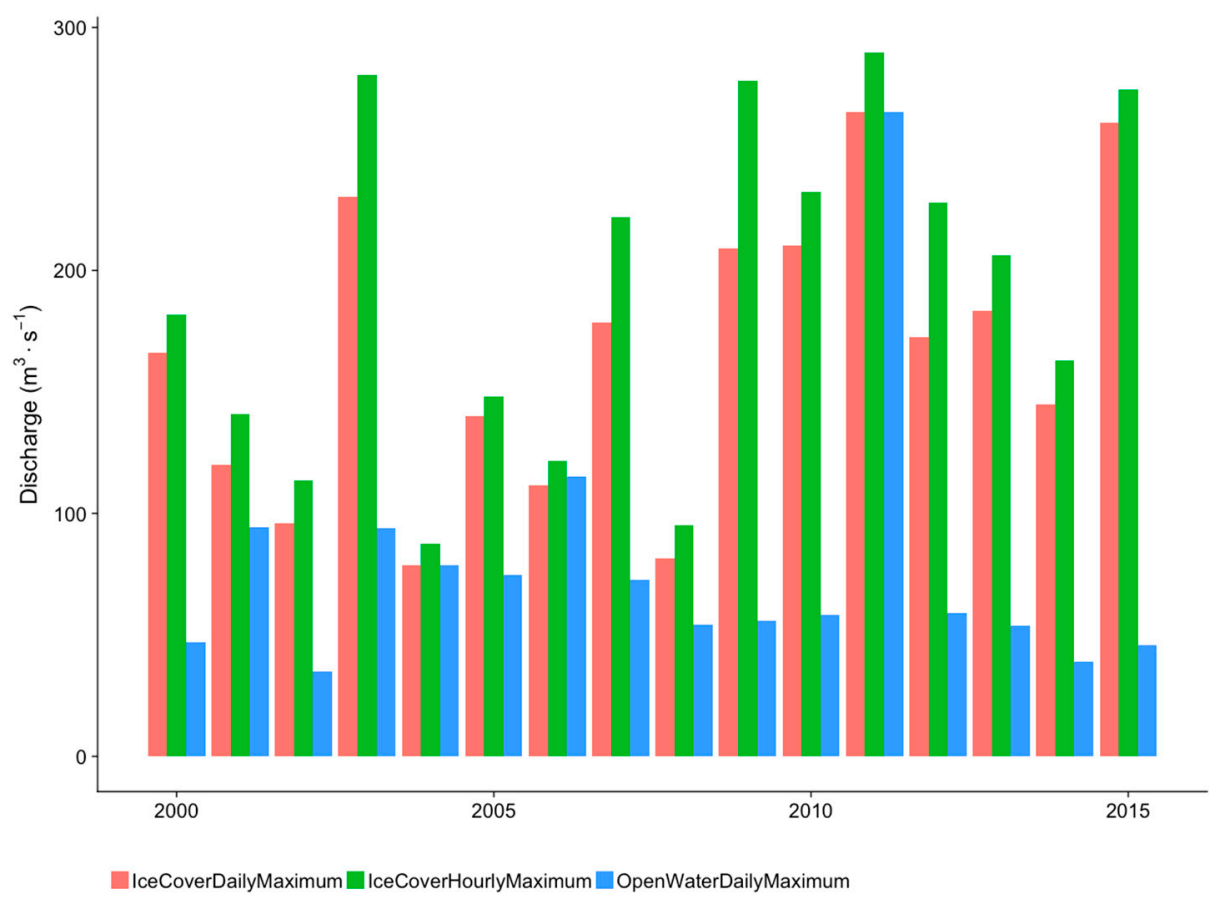

Figure 4. Comparison of winter 1-day maximum, computed for open water conditions (ice-corrected data with a daily time resolution, OpenWaterDailyMaximum), 1-day maximum from hourly raw data (IceCoverHourlyMaximum), and the 1-day maximum for daily raw data (IceCoverDailyMaximum). Note that for 2004, 2006, and 2011, the spring flood occurred in late March; therefore, the daily open water discharge with and without ice is similar and the hourly discharge represents the instantaneous hourly peak.

Based on the data in Figure 4, we see that the ice signal is also present in the daily averaged data, albeit somewhat reduced, but is still marked enough for analysis on a daily time scale to give an indication of the effects of ice on the discharge conditions. In cases in which an early spring flood affects the maximum peak during the winter season, the period of analysis could be shortened to eliminate this from the analysis. Other ice-induced peaks that occur before the start of the spring flood will still be detected. This can be seen by summarizing the number of events larger than $5 \mathrm{~h}$ for the winters from 2000/2001 to 2015/2016 (Table 4), noting that winters 2004, 2006, and 2011 all show several peaks.

Table 4. The number of ice-induced events larger than $5 \mathrm{~h}$. The year number indicates the start of the winter (2000—winter 2000/2001).

\begin{tabular}{ccccccccccccccccc}
\hline Year & $\mathbf{2 0 0 0}$ & $\mathbf{2 0 0 1}$ & $\mathbf{2 0 0 2}$ & $\mathbf{2 0 0 3}$ & $\mathbf{2 0 0 4}$ & $\mathbf{2 0 0 5}$ & $\mathbf{2 0 0 6}$ & $\mathbf{2 0 0 7}$ & $\mathbf{2 0 0 8}$ & $\mathbf{2 0 0 9}$ & $\mathbf{2 0 1 0}$ & $\mathbf{2 0 1 1}$ & $\mathbf{2 0 1 2}$ & $\mathbf{2 0 1 3}$ & $\mathbf{2 0 1 4}$ & $\mathbf{2 0 1 5}$ \\
\hline Duration & 22 & 7 & 9 & 8 & 7 & 7 & 7 & 6 & 6 & 3 & 5 & 20 & 6 & 13 & 18 & 19 \\
\hline
\end{tabular}

To compare changes in effects before and after hydropower regulation, indexes were computed for the pre-regulation and post-regulation period on daily data and the results were compared. All measurements are taken from the Syrstad gauge, but it is worth noting that the measurement site pre-regulation was originally a kilometer downstream from the current gauge and was then 
moved, since the old measurement site was affected by the construction of the Bjørset dam and intake. The series is later spliced by NVE and adjusted to the Syrstad site.

Figure 5 shows the 1-day peak discharge before and after the regulation. There is a significant difference $(p<0.05)$ between peak sizes before and after the regulation. From the figure, we can see that ice had an effect on the flow also before the regulation, and that this has increased after the regulation due to loss of ice cover and a more dynamic ice regime. The effect of ice on the natural flow regime regarding timing of occurrence here is similar to what is seen in panel B of Figure 3.

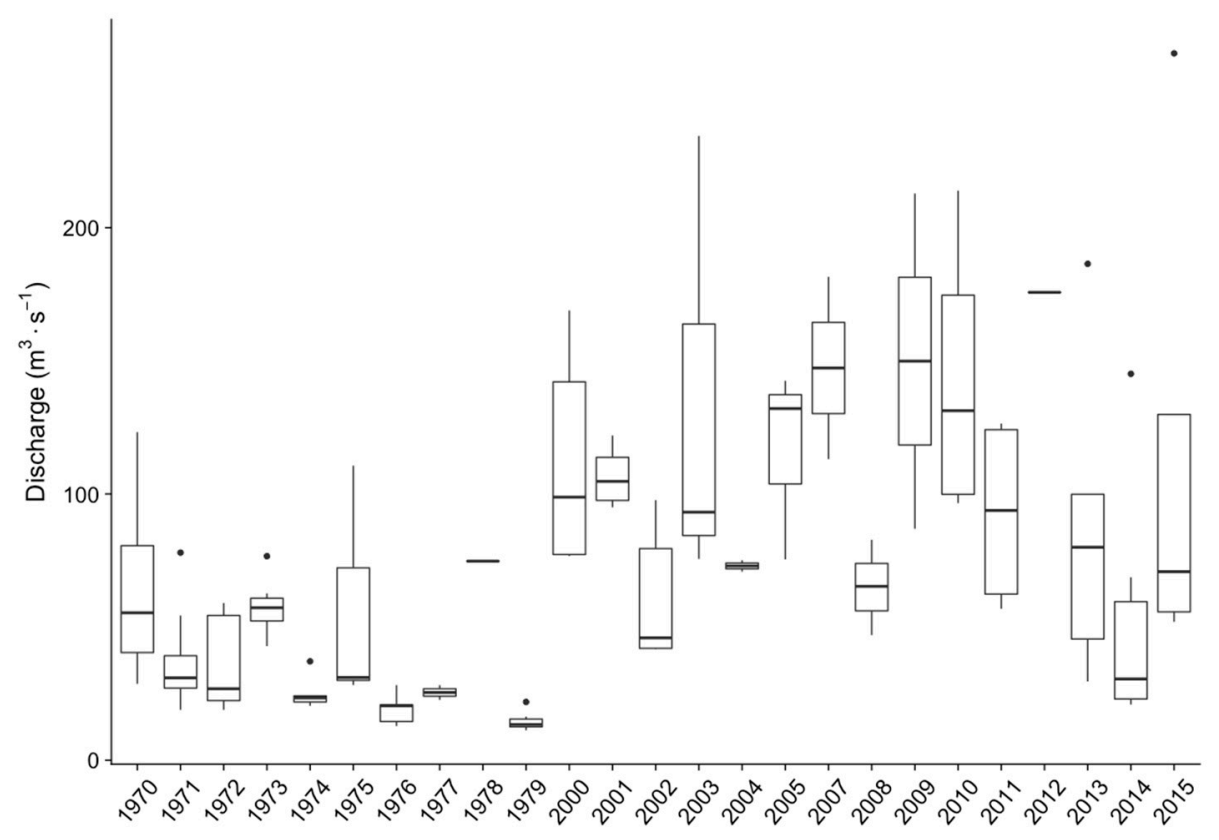

Figure 5. Ice-induced peak discharges before regulation (winters 1970/1971-1979/1980) and after regulation (winters 2000/2001-2015/2016). The bold line is the median, the box shows the interquartile range(IQR), the whiskers $1.5 \cdot \mathrm{IQR}$, and the circles show outliers.

In Figure 6, a similar comparison is made between the size of daily rises and falls in ice-induced peaks identified in the hydrograph. The difference between drops and rises are also significantly different $(p<0.05)$, with larger drops and rises in discharge after the regulation. Regarding the duration of the peaks, there is no significant difference before and after the regulation. We get more and larger peaks, but the duration of each event is not very different in the regulated and unregulated case. The plot in Figure 7 shows the winter mean index commonly used in the application of IHA in Norway for 10 years before regulation and 16 years after regulation. The plot shows the difference between uncorrected data and ice-corrected data on an important parameter in cold climate impact assessment, and it also illustrates the effect hydropower regulation typically has on the flow regime through increased winter discharge. 
A

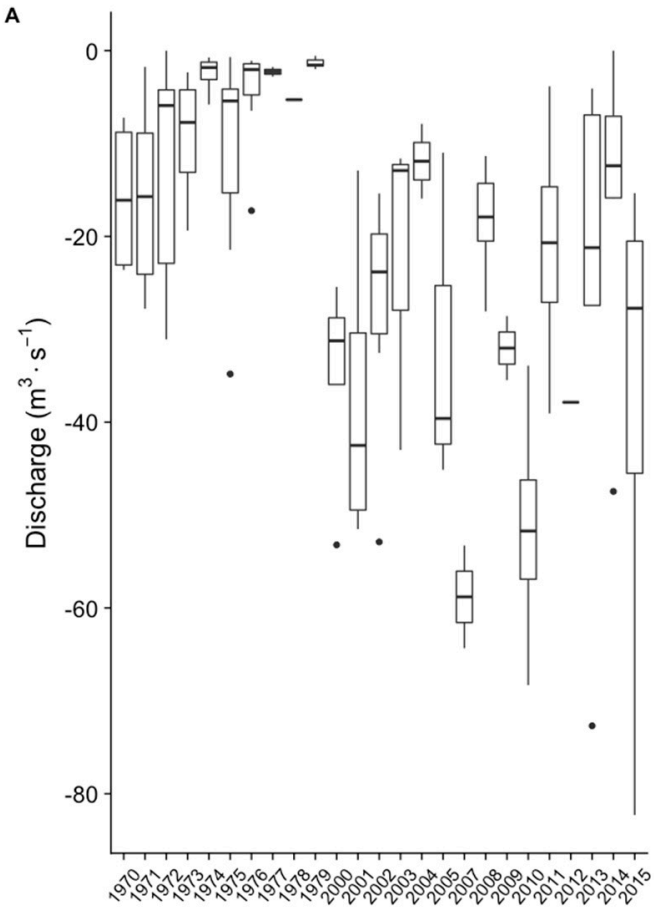

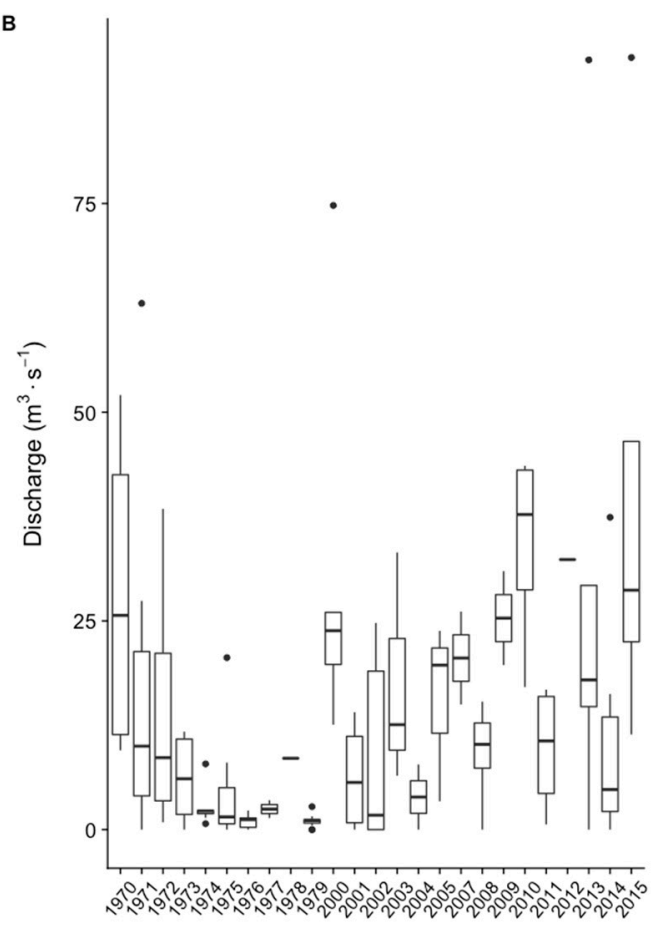

Figure 6. Drops (panel (A)) and rises (panel (B)) for the pre- and post-regulation periods.

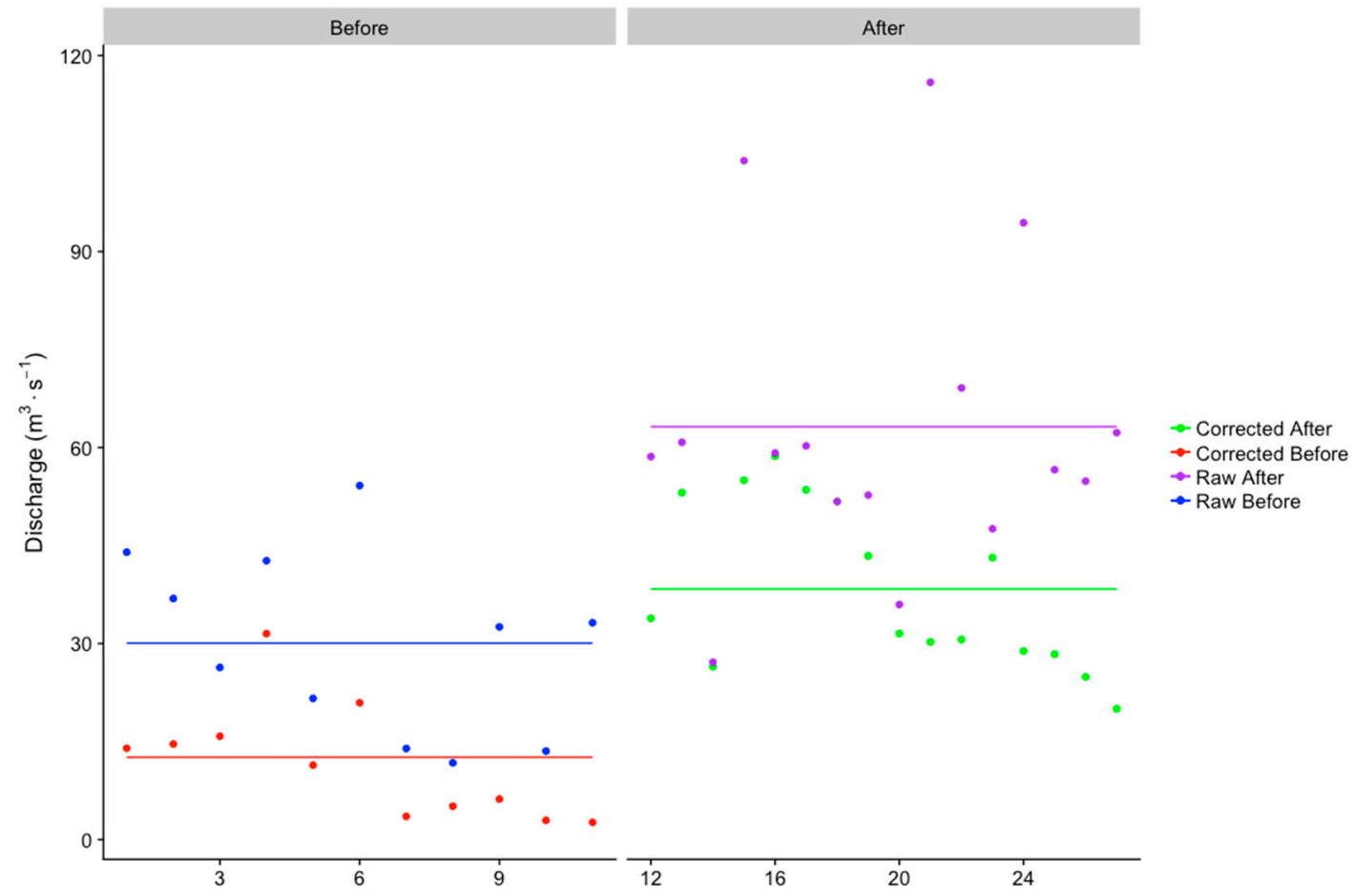

Figure 7. Average winter flow before regulation (year 1-10) for corrected and raw data (red and blue, respectively) and after regulation (year 12-26) for corrected and raw data (green and purple, respectively). The whole lines show the mean of each category of data.

\section{Discussion}

For many evaluations of flow regimes in rivers during winter, open water data is used even if it is well known that formation and break-up of ice can have a large impact on the flow regime. This paper 
presents a set of indices that can be used to describe the effect ice has on flow in winter in rivers, information that may be important in environmental analysis during the cold season. The indices are mainly developed for assessing effects of flow regulations in winter, which is known to influence ice formation and ice production [35]. The work builds on the work by Richter, Baumgartner, Powell, and Braun [7] and follows the principles of the Index of Hydrological Alteration. The method presented will add functions to the first cold regions indices, the Cold Region Hydrological Indicators of Change, developed by Peters, Monk, and Baird [27]. The indices presented here adds measures handling duration and frequency of ice-induced peaks and the rise and fall rates of such peaks. These are measures that are particularly relevant for smaller streams with dynamic ice regimes. The evaluation of the differences between recorded raw data and ice-corrected data as shown also highlights the importance of using the right winter data for the analysis and that winter data, without a clear status regarding if they are ice-influenced or not should, should be applied with care.

The derivation of the indexes and the analysis carried out here utilizes the official quality-controlled and ice-corrected data available for many Norwegian gauges operated by Norwegian Water Resources and Energy Directorate (NVE). The ice correction is carried out by NVE to provide discharge series that shows the true inflow from the catchment during winter. The analysis approach is an alternative to the method used by Peters, Monk, and Baird [27], who utilized meta data available in the Canadian discharge database to identify ice-influenced flow periods. Since such information is not available for Norway; the approach used here is to combine the corrected data with the raw data showing the effect of ice formation. The analysis is therefore dependent on the accuracy in the ice corrections, and uncertainties in the corrections will lead to uncertainties in the computed indices. For the study site at Syrstad, the ice corrections should be precise, since both releases from upstream hydropower stations and the production discharge from a downstream station are available. In case such data is missing, a crude approximation can be made from temperature to identify periods in which ice may have an impact on the flow regime. As seen from the results presented here, this will mostly be an approximation, and little quantitative data can be reliably derived from this approach. An alternative approach in the case corrections or meta data on ice is missing-that is, applying a hydrological model to derive the natural inflow to the catchment as a basis for evaluating the magnitude of ice impacts. In this case, the simulated inflow at the gauge could be used as a replacement for the ice-corrected flow data used in this study. Independent of the method used, data for winter length and, particularly, ice cover stability may be difficult to assess without specific ice data for the sites.

The results from the analysis capture the ice dynamics of the flow regime as described in recent literature [13-15], and the evaluation of differences between regulated and natural streams also confirms previous studies on extended ice formation period in rivers regulated from hydropower due to releases of warmer reservoir water into the downstream rivers. The results from this analysis show that, for the rivers studied, data with an hourly time resolution captures more of the dynamics of the ice-flow regime regarding the number of peaks, peak size, and the rate of change than what is seen in the data with a daily resolution. When data are subsequently aggregated into daily time resolution, the signal from short duration ice events are reduced or even removed from the data. On the other hand, since ice-corrected data with an hourly time resolution is not available, one should be careful not to attribute natural instantaneous peaks in the hourly data to ice driven events. For some sites, finer time resolution than one day could be important information related to environmental effects, e.g., Stickler et al. [36] and Alfredsen et al. [37] showed sub-daily responses in Atlantic salmon during several ice formation and release events in the river Orkla. The loss of detail in the daily ice data is, in many ways, similar to the loss of accuracy experienced when analyzing hydro-peaking flow data, e.g., Bevelhimer et al. [38] found that a sub-daily time step is necessary to capture the dynamics of a peaking flow regime. As discussed, it is a drawback that the assessment of hourly peaking relies on daily ice-corrected data. Further, it can also be a problem that hourly data mainly are available for the recent decades, and such data are typically not available for the time periods that are often needed to 
define the pre-regulation flow conditions. However, as shown in Figures 4 and 7, there is still an ice signal in the daily data, and it is possible to draw information on both timing and the effects ice has on the flow regime.

In a natural river, the winter season often can be divided into a freeze-up period, a stable mid-winter period, and a breakup period, of which each has distinct processes. The typical freeze-up effects are shown in Figure 3B, and the same figure also shows effects of releases of ice on the flow measurements. In a regulated river with releases of production water from reservoirs, the mid-winter, stable ice period is often reduced or completely removed and replaced with a more dynamic ice formation [21], as is seen in Figure 3A. The method described here will catch the temporal distribution of ice effects, and as seen in Table 3, events are timed and identified through the winter period.

A source of uncertainty associated with station-based analysis of hydrologic variability, as presented here, is if the method properly catches the spatial variability of the hydrologic regime in the river. This is even more important for assessment of ice effects than for the open water hydrological analysis, since the spatial variability of ice is larger than the variability of the flow alone, and is also driven by local hydraulic and morphological conditions and the energy balance of the river section. We can assume that observed, ice-induced low flows in a river probably mean that there are extensive ice formations and, likely also, ice-induced high flow at another location in the same river reach. This can be remedied by having a network of discharge gauges along the river, but, at least for Norway, there are few rivers that have the necessary spatial detail in their measurement networks. An option to overcome this is to model ice formation along the river reach and use this to develop a spatially distributed hydrological index. Timalsina, Charmasson, and Alfredsen [11] showed the possibility of simulating ice development along the Orkla river using the MIKE-ICE model, and the findings could have been used to improve the hydrological assessment. The drawbacks of this approach is the significant data needed and the potential problems with setting up the model in smaller and steeper rivers with an even more dynamic ice regime. Turcotte, Morse, Dube, and Anctil [16] presented an energy balance model that can be used to describe ice processes and quantify ice formation in steep rivers, which could be used as a tool to establish the ice regime and thereby better understand the spatial variability of the hydrological indices. This approach is an interesting way to better describe the ice regime of a river, but it also requires detailed data on climate and morphology with a spatial resolution that may not be available for many sites. A third option would be to use river classification or river mapping system on meso-scale, which is applied in many environmental studies, e.g., [39,40]. This is a rapid method of classifying river sections according to simple morphological and hydraulic parameters, and it could be combined with knowledge on ice processes to map probable sites where ice will have an effect on the flow regime, and then this information could be used to assess the spatial distribution of the ice effects measured at the gauge site. Typically, the classification systems' map riffles, runs, and pools, which will have different ice formation processes, and this could then be related to the type of river found at the gauge site.

Figure 8 shows a section of the river Orkla mapped into river types. The Syrstad gauge is indicated on the map in a river type (shallow glide), which can have large frazil ice accumulations in winter, which explains the ice effects on the flow, as seen, e.g., in Figure 2. By comparing river types, the extent of possible sites with similar ice regimes can be found, and, thereby, the spatial distribution of similar ice effects, as observed at the gauge site, can be evaluated. This method can be improved by more field data to confirm the ice formation processes. The linkage between river types and ice formation can be further developed, e.g., by utilizing a statistical model as described by Lind, Alfredsen, Kuglerova, and Nilsson [12] to link simple parameters on river type to ice types and ice processes, and if more detail is needed this could further be developed into a spatial model using a strategy similar to the method described by Lindenschmidt and Chun [41]. This could lead to a method that provides some modelling capability at the same time as it preserves the desired simplicity of the hydrological index method. A similar strategy could be to explore the possibility of linking the hydrological ice indexes to the conceptual ice model developed by Turcotte and Morse [42]. This method links ice cover formation 
with ice formation processes using simple parameters like channel type, channel size, and winter intensity that can easily be found for any river. This model could also be combined with data from the river classification shown in Figure 8 to give an overview of both the spatial and temporal aspect of ice formation. An important factor to consider when these models are applied to rivers like Orkla at Syrstad is the effect of the hydropower regulation, and a system like the one in Orkla with several reservoir and power plants will have a large effect on the flow regime and the spatial distribution of ice. This must be considered when existing tools developed for natural conditions are used in regulated rivers.

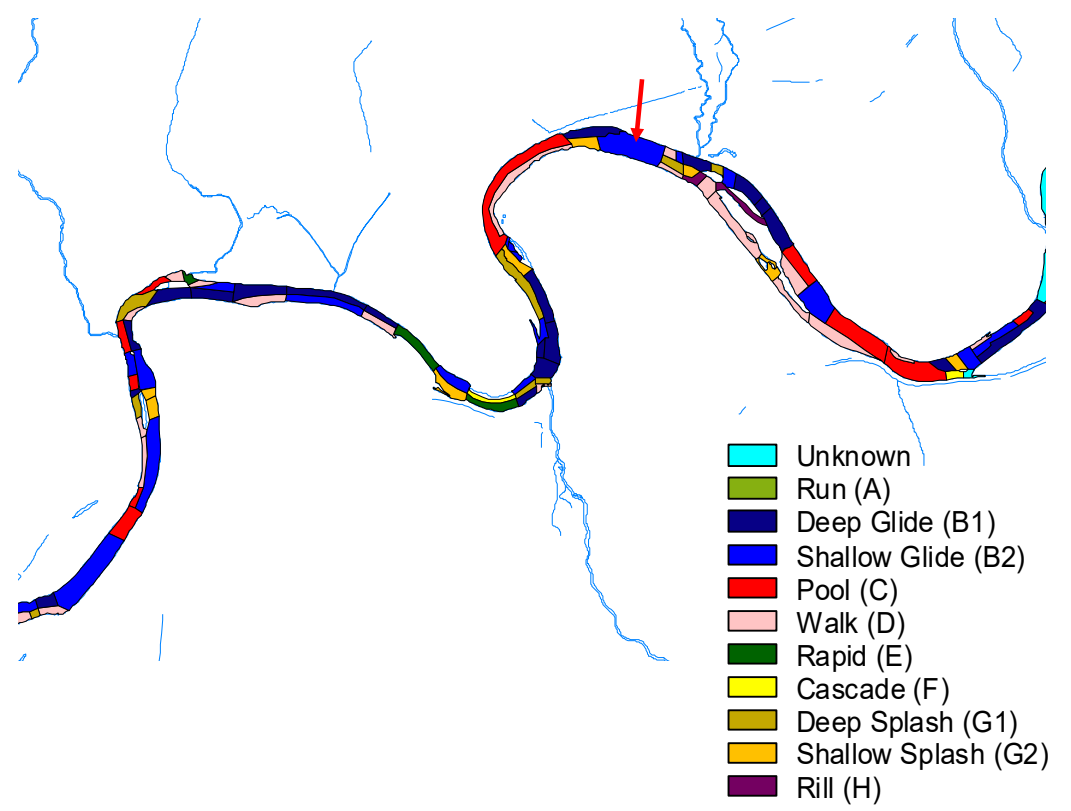

Figure 8. A section of the Orkla river mapped by the classification system described by [39]. The arrow indicates the position of the Syrstad gauge located in a shallow glide, which shows frazil ice accumulation over winter.

The indexes presented here will be directly useful as a complement to the existing tools when measuring the before and after situation in rivers with a regulated discharge. In addition, in the recent measures for hydro-morphological effects made for the water framework directive in Norway [9], ice effects are categorized on a scale from natural to severely modified based on percentage changes in ice cover and/or anchor ice formation. This is data that can be difficult to find directly from measurements, so the derivation of data needed for this assessment must in many cases be based on proxy information. The indices of ice-induced flow effects could be used to evaluate the categories in this classification. The frequency, duration, and temporal distribution of ice-induced peaks could be related to reduced stability of the ice regime, and they are direct effects of the formation of frazil and anchor ice in the river section.

The use of hydrological indexes presented here is mainly focused on river regulations and a situation in which we compare the flow situation before and after the regulation to determine changes that can be critical to the environment and as a basis for finding and evaluating mitigation measures. From this application, it follows that the method also can be used to identify ice effects on a hydrograph and as a measure of the impact of ice on discharge and water levels also in natural rivers, e.g., as a tool for assessing effects of vegetation as shown by Lind and Nilsson [23]. The method is also applicable to other types of studies in which measures of changes in the hydrology are useful. Bin Ashraf et al. [43] use the index of hydrologic alteration to evaluate climate change effects on flow regimes in rivers in Finland. If ice is a case in climate change studies, the combination of changes in temperature and the current indexes of ice-induced flow changes could be used to assess future 
ice effects. Linnansaari et al. [44] showed that ice had an effect on how Atlantic salmon utilized an artificial habitat in a regulated river, and unpublished data from the same river shows significant ice-driven modification to the water level and thereby the function of the habitat in the same river. The method presented here could be used to evaluate ice effects in such reaches by combining local measurements with a base flow assessment from an upstream unregulated gauge.

\section{Conclusions}

In combination with the standard indexes of hydrological alteration that give a measure of the true inflow to the catchment, the indexes presented here measure ice modifications to the flow and thereby to relevant habitat characteristics in the river that are directly influenced by the retention, release, and water level increases caused by ice. The proposed ice indexes presented here should, therefore, together with the indexes presented by Peters, Monk, and Baird [27], provide a useful supplement to the open water indexes when impacts of ice on the environment need to be addressed. The results shown here also illustrate the importance of consistency in data used for winter analysis, and the possible effects encountered by utilizing data without ice correction or winter data without any indication if ice has an effect on the discharge or not.

The spatial heterogeneity of ice formation in particularly small rivers may not be properly covered by the gauge-based method presented here. It is, therefore, necessary to be careful if data is extrapolated from the site to larger sections of river, and preferably this should be done with some underlying knowledge of how ice formation processes vary along the river system.

Acknowledgments: A first version of this article was presented at the CRIPE 2017 conference, and the author wishes to acknowledge the comments and input from the discussion at the conference. The author also thanks Dr. Tor Haakon Bakken for providing preliminary data on the hydro morphological indexes developed for the implementation of the water framework directive in Norway. I also wish to thank two anonymous reviewers for their comments to the manuscript.

Conflicts of Interest: The author declares no conflict of interest.

\section{References}

1. Arthington, A.H.; Bunn, S.E.; Poff, N.L.; Naiman, R.J. The challenge of providing environmental flow rules to sustain river ecosystems. Ecol. Appl. 2006, 16, 1311-1318. [CrossRef]

2. Poff, N.L.; Allan, J.D.; Bain, M.B.; Karr, J.R.; Prestegaard, K.L.; Richter, B.D.; Sparks, R.E.; Stromberg, J.C. The natural flow regime. BioScience 1997, 47, 769-784. [CrossRef]

3. Poff, N.L.; Richter, B.D.; Arthington, A.H.; Bunn, S.E.; Naiman, R.J.; Kendy, E.; Acreman, M.; Apse, C.; Bledsoe, B.P.; Freeman, M.C.; et al. The ecological limits of hydrological alteration (ELOHA): A framework for developing regional flow standards. Freshw. Biol. 2010, 55, 147-170. [CrossRef]

4. Acreman, M.C.; Dunbar, M.J. Defining environmental flow requirements-A review. Hydrol. Earth Syst. Sci. 2004, 8, 861-876. [CrossRef]

5. Tharme, R.E. A global perspective on environmental flow assessment; emerging trends in the development and application of environmental flow methodologies for rivers. River Res. Appl. 2003, 19, 397-441. [CrossRef]

6. Poff, N.L.; Zimmerman, J.K.H. Ecological responses to altered flow regimes: A literature review to inform the science and management of environmental flows. Freshw. Biol. 2010, 55, 194-205. [CrossRef]

7. Richter, B.D.; Baumgartner, J.V.; Powell, J.; Braun, D.P. A method for assessing hydrologic alteration within ecosystems. Conserv. Biol. 1996, 10, 1163-1174. [CrossRef]

8. Forseth, T.; Harby, A. Handbook for Environmental Design in Regulated Salmon Rivers; NINA: Trondheim, Norway, 2014; Volume 53, p. 90.

9. Bakken, T.H.; Forseth, T.; Harby, A. Assessment of Hydro-Morphological State and Reference Conditions in Regulated Rivers; SINTEF Energy: Trondheim, Norway, 2017.

10. Olden, J.D.; Poff, N.L. Redundancy and the choice of hydrologic indices forcharacterizing streamflow regimes. River Res. Appl. 2003, 19, 101-121. [CrossRef] 
11. Timalsina, N.P.; Charmasson, J.; Alfredsen, K.T. Simulation of the ice regime in a norwegian regulated river. Cold Reg. Sci. Technol. 2013, 94, 61-73. [CrossRef]

12. Lind, L.; Alfredsen, K.; Kuglerova, L.; Nilsson, C. Hydrological and thermal controls of ice formation in 25 boreal stream reaches. J. Hydrol. 2016, 540, 797-811. [CrossRef]

13. Nafziger, J.; She, Y.; Hicks, F.; Cunjak, R.A. Anchor ice formation and release in small regulated and unregulated streams. Cold Reg. Sci. Technol. 2017, 141, 66-77. [CrossRef]

14. Stickler, M.; Alfredsen, K.T.; Linnansaari, T.; Fjeldstad, H.-P. The influence of dynamic ice formation on hydraulic heterogeneity in steep streams. River Res. Appl. 2010, 26, 1187-1197. [CrossRef]

15. Turcotte, B.; Morse, B. Ice processes in a steep river basin. Cold Reg. Sci. Technol. 2011, 67, 146-156. [CrossRef]

16. Turcotte, B.; Morse, B.; Dube, M.; Anctil, F. Quantifying steep channel freezeup processes. Cold Reg. Sci. Technol. 2013, 94, 21-36. [CrossRef]

17. Turcotte, B.; Alfredsen, K.; Beltaos, S.; Burrell, B.C. Ice-related floods and flood delineation along streams and small rivers. In Proceedings of the 19th Workshop on the Hydraulics of Ice Covered Rivers, Whitehorse, YT, Canada, 10-12 July 2017; CGU HS Committee on River Ice Processes and the Environment: Whitehorse, YT, Canada, 2017; p. 26.

18. Gridley, N.C.; Prowse, T.D. Physical effects of river ice. In Environmental Aspects of River Ice; Prowse, T.D., Gridley, N.C., Eds.; National Hydrology Research Institute: Saskatoon, SK, Canada, 1993; Volume 1, pp. 3-75.

19. Hedger, R.D.; Næsje, T.F.; Fiske, P.; Ugedal, O.; Finstad, A.; Thorstad, E.B. Ice-dependent winter survival of juvenile atlantic salmon. Ecol. Evol. 2013, 3, 523-535. [CrossRef] [PubMed]

20. Brown, R.S.; Hubert, W.A.; Daly, S.F. A primer on winter, ice and fish: What fisheries biologists should know about winter ice processes and stream-dwelling fish. Fisheries 2011, 36, 8-26. [CrossRef]

21. Huusko, A.R.I.; Greenberg, L.; Stickler, M.; Linnansaari, T.; Nykänen, M.; Vehanen, T.; Koljonen, S.; Louhi, P.; Alfredsen, K. Life in the ice lane: The winter ecology of stream salmonids. River Res. Appl. 2007, 23, 469-491. [CrossRef]

22. Heggenes, J.; Alfredsen, K.; Bustos, A.A.; Huusko, A.; Stickler, M. Be cool: A review of hydro-physical changes and fish responsesin winter in hydropower-regulated northern streams. Environ. Biol. Fishes 2017, 21, 1-21. [CrossRef]

23. Lind, L.; Nilsson, C. Vegetation patterns in small boreal streams relate to ice and winter floods. J. Ecol. 2015, 103, 431-440. [CrossRef]

24. Lind, L.; Nilsson, C.; Polvi, L.E.; Weber, C. The role of ice dynamics in shaping vegetation in flowing waters. Biol. Rev. 2014, 89, 791-804. [CrossRef] [PubMed]

25. Lesack, L.F.W.; Marsh, P. River-to-lake connectivities, water renewal, and aquatic habitat diversity in the mackenzie river delta. Water Resour. Res. 2010, 46, 16. [CrossRef]

26. Monk, W.A.; Peters, D.L.; Baird, D.J. Assessment of ecologically relevant hydrological variablesinfluencing a cold-region river and its delta: The athabascariver and the peace-Athabasca delta, northwestern Canada. Hydrol. Process. 2012, 26, 1827-1839. [CrossRef]

27. Peters, D.L.; Monk, W.A.; Baird, D.J. Cold-regions hydrological indicators of change (CHIC) for ecological flow needs assessment. Hydrol. Sci. J. 2014, 59, 502-516. [CrossRef]

28. Gebre, S.B.; Alfredsen, K.T. Investigation of river ice regimes in some norwegian water courses. In Proceedings of the 16th Workshop on the Hydraulics of Ice Covered Rivers, Winnipeg, MB, Canada, 18-22 September 2011; CGU HS Committee on River Ice Processes and the Environment: Winnipeg, MB, Canada, 2011; pp. 1-20.

29. Alfredsen, K. Incorporating ice effects in environmental flow indices. In Proceedings of the 19th Workshop on the Hydraulics of Ice Covered Rivers, Whitehorse, YT, Canada, 10-12 July 2017; CGU HS Committee on River Ice Processes and the Environment: Whitehorse, YT, Canada, 2017.

30. Prowse, T. River Ice Ecology; National Water Research Institute, Environment Canada: Burlington, ON, Canada, 2000.

31. Casas-Mulet, R.; Alfredsen, K.; Hamududu, B.; Timalsina, N.P. The effects of hydropeaking on hyporheic interactions based on field experiments. Hydrol. Process. 2014. [CrossRef]

32. Gebre, S.; Alfredsen, K. Contemporary trends and future changes in freshwater ice conditions: Inference from temperature indices. Hydrol. Res. 2014, 45, 455-478. [CrossRef]

33. Finstad, A.G.; Forseth, T.; Faenstad, T.F.; Ugedal, O. The importance of ice cover for energy turnover in juvenile atlantic salmon. J. Anim. Ecol. 2004, 73, 959-966. [CrossRef] 
34. R-Development Core Team. R: A Language and Environment for Statistical Computing; R Foundation for Statistical Computing: Vienna, Austria, 2011.

35. Gebre, S.; Alfredsen, K.; Lia, L.; Stickler, M.; Tesaker, E. Ice effects on hydropower systems—A review. J. Cold Reg. Eng. 2013, 27, 196-222. [CrossRef]

36. Stickler, M.; Alfredsen, K.; Scruton, D.A.; Pennell, C.; Harby, A.; Økland, F. Mid-winter activity and movement of atlantic salmon parr during ice formation events in a norwegian regulated river. Hydrobiologia 2007, 582, 81-89. [CrossRef]

37. Alfredsen, K.; Stickler, M.; Scruton, D.A.; Pennel, C.J.; Kelley, C.; Halleraker, J.H.; Harby, A.; Fjeldstad, H.-P.; Heggenes, J.; Økland, F. A telemetry study of winter behaviour of juvenile atlantic salmon (salmo salar) in a river with a dynamic ice regime. In Proceedings of the 5th International Symposium on Ecohydraulics, Madrid, Spain, 12-17 September 2004; de Jalon Lastra, D., Martinez, P., Eds.; International Association of Hydraulic Research: Madrid, Spain, 2004; Volume 1, pp. 133-139.

38. Bevelhimer, M.S.; McManamay, R.A.; O'Connor, B. Characterising sub-daily flow regimes: Implications of hydrologic resolution on ecohydrology. River Res. Appl. 2014. [CrossRef]

39. Borsanyi, P.; Alfredsen, K.; Harby, A.; Ugedal, O.; Kraxner, C. A meso-scale habitat classification method for production modelling of atlantic salmon in norway. Hydroecol. Appl. 2004, 14, 119-138. [CrossRef]

40. Parasiewicz, P. The mesohabsim model revisited. River Res. Appl. 2007, 23, 893-903. [CrossRef]

41. Lindenschmidt, K.-E.; Chun, K.P. Geospatial modelling to determine the behaviour of ice cover formation during freeze-up of the dauphin river in manitoba. Hydrol. Res. 2014, 45, 645-659. [CrossRef]

42. Turcotte, B.; Morse, B. A global river ice classification model. J. Hydrol. 2013, 507, 134-148. [CrossRef]

43. Ashraf, F.B.; Haghighi, A.T.; Marttila, H.; Kløve, B. Assessing impacts of climate change and river regulation on flow regimes in cold climate: A study of a pristine and a regulated river in the sub-arctic setting of northern europe. J. Hydrol. 2016, 542, 410-422. [CrossRef]

44. Linnansaari, T.; Alfredsen, K.; Stickler, M.; Arnekleiv, J.V.; Harby, A.; Cunjak, R.A. Does ice matter? Site fidelity and movements by atlantic salmon (salmo salar L.) parr during winter in a substrate enhanced river reach. River Res. Appl. 2009, 25, 773-787. [CrossRef]

(C) 2017 by the author. Licensee MDPI, Basel, Switzerland. This article is an open access article distributed under the terms and conditions of the Creative Commons Attribution (CC BY) license (http:/ / creativecommons.org/licenses/by/4.0/). 